\title{
STUDI KUAT PENAMPANG ABUTMEN BETON BERTULANG DENGAN MUKA PENAMPANG YANG MIRING HORIZONTAL. JALAN TOL PANDAAN - MALANG JAWA TIMUR
}

\author{
Rahmat Hidayatullah ${ }^{1}$, Ir. Pujo Priyono, MT $^{2}$, Adhitya Surya Manggala ST, MT $^{3}$ \\ Study Program of Civil engineering, Faculty of Engineering, MuhammadiyahUniversity of \\ Jember \\ J1. Karimata 49,Jember 68121, Indonesia \\ Email : Rahmathidayatullahh@gmail.com
}

\begin{abstract}
One important element in the bridge is located on the abutments of the bridge, where the abutments carry the load at the top of the bridge that is planned to use the crosssection of reinforced concrete the field of contact oblique to the horizontal that the results obtained from the safe with the range of variation of slope on cross-section is in particular on the bridge Pandaan-Malang.

With different angles of inclination which varies, for a slope of 0 degrees can be concluded controlled press, while for a slope of 15 degrees can be concluded controlled press for a reinforcement ratio of 0.00 and 0.25 while for a reinforcement ratio of 0.5 and 0.75 restrained tensile den with a slope of 40 degrees can be concluded controlled press.

For the existing condition of his own who were in the field with a slope of 10 degrees the reinforcement ratio of 0.75 can be simpilkan controlled pull.
\end{abstract}

Keywords : Abutments, slope angle,reinforcement ratio. 


\section{PENDAHULUAN}

Indonesia adalah salah satu negara berkembang yang sedang giat malaksanakan pembangunan di segala bidang.Jalan sebagai salah satu prasarana transportasi, mempunyai peranan yang penting di dalam kelancaran transportasi untuk pemenuhan hidup.Sehingga jalan yang lancar, aman dan nyaman telah menjadi kebutuhan hidup utama.

Jembatan adalah suatu konstruksi yang berfungsi untuk melewatkan lalu lintas yang terputus pada kedua ujungnya akibat adanya hambatan berupa : sungai/ lintasan air,lembah, jalan / jalan kereta api yang menyilang dibawahnya. Struktur bawah jembatan adalah pondasi. Suatu sistem pondasi harus dihitung untuk menjamin keamanan,kestabilan bangunan diatasnya, tidak boleh terjadi penurunan sebagian atau seluruhnya melebihi batas-batas yang diinginkan (Demetrios E.Trionas,P.E ,2002).

Secara garis besar konstruksi jembatan terdiri dari dua komponen utama yaitu bangunan atas (super structure/upper structure) dan bangunan bawah (sub structure).Bangunan atas merupakan bagian jembatan yang menerima langsung beban dari orang dan kendaraan yang melewatinya. Bangunan atas terdiri dari komponen utama yaitu lantai jembatan, rangka utama, gelagar melintang, gelagar memanjang,diafragma, pertambatan dan perletakan/andas. Selain itu juga terdapat kompenen penunjang pada bangunan atas yaitu trotoar, perlengkapan sambungan, ralling, pagar jembatan, drainase, penerangan dan parapet. Bangunan bawah merupakan bagian jembatan yang menerima beban dari bangunan atas ditambah tekanan tanah dan gaya tumbukan dari perlintasan di bawah jembatan. Bangunan bawah meliputi pilar jembatan (pier), pangkal jembatan (abutment) dan pondasi.
Abutment atau kepala jembatan merupakan bagian bawah bangunan jembatan.Abutment mempunyai fungsi untuk memikul semua beban yang bekerja pada bangian atas jembatan, serta berfungsi untuk meneruskan beban yang dipkul bangunan atas kelapisan tanah dasar dengan aman sekaligus sebagai bangunan penahan tanah serta menerima tekanan dan di teruskan ke pondasi.

Mengingat belum adanya
teori yang menguatkan untuk
mendesain penampang beton
bertulang dengan muka yang miring
horizontalkami tertarik untuk
mengevaluasi lebih jauh tentang "Studi kuat penampang AbutmenBeton Bertulang dengan Muka Penampang yang Miring Horizontal ". (Studi Kasus Jembatan jalan Tol Pnadaan - Malang Jawa Timur).

Dari uraian diatas, masalah yang akan dibahas dalam Tugas Akhir ini adalah sebagai berikut:Bagaimanakah kuat penampang abutmen beton bertulangyang bidang kontaknya miring,Bagaimana kuat penampang abutmen yang bidang kontaknya miring horizontal terhadap timbunan tanah di belakang abutment.

\section{METODE PENELITIAN}

\section{Lokasi Proyek}

Secara administratif lokasi proyek jalan tol Pandaan - Malang berada di Kabupaten Pasuruan dan Kabupaten Malang, Jembatan yang di tinjau berada di seksi 2 STA 15 + 916 pada desa Parerejo, Kecamatan Purwodadi - pasuruan. 


\section{Kerangka Pemikiran}

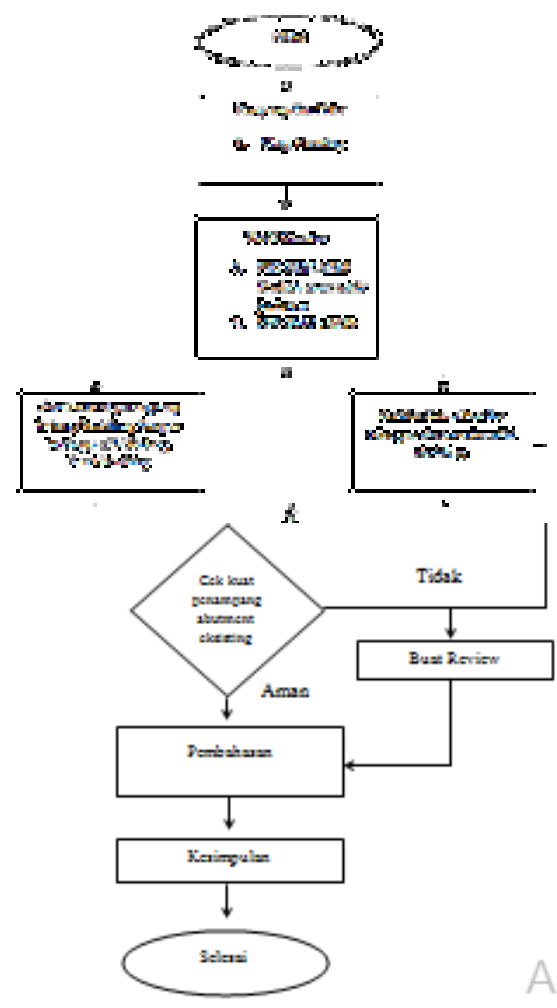

Gambar 1. Flowchart

\section{ANALISA DAN}

PEMBAHASAN

Balok penampang persegi memikul lentur murni bertulangan tunggal

Keadaan setimbang (balance) pada keadaan batas. (Gambar 4.1)

Dimanar $=\sqrt{ }\left(b^{2}+(b \cdot \operatorname{tg} \alpha)^{2}\right.$

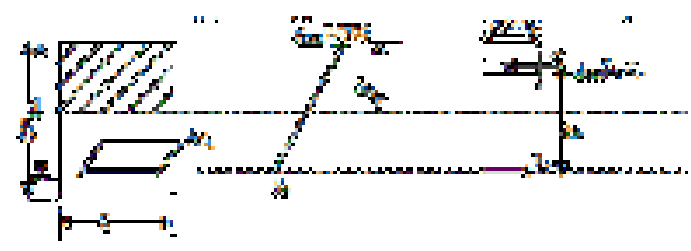

Gambar 4.1. Penampang dengandiagram regangan dan tegangan keadaan setimbang.

Pada keadaan setimbang :

$\varepsilon_{\mathrm{c}}=0,003 \quad$ (regangan ultimit beton,SNI2847-2013,pasal10.3.2)

$\varepsilon_{\mathrm{s}}=\varepsilon_{\mathrm{y}}$ (regangan baja pada keadaan leleh)

Dari hukum segitiga sebangun: $\mathrm{c}_{\mathrm{b}}: \mathrm{d}=\varepsilon_{\mathrm{c}}:\left(\varepsilon_{\mathrm{s}}+\varepsilon_{\mathrm{c}}\right)$

$\mathrm{c}_{\mathrm{b}} / \mathrm{d}=\frac{0,003}{\left(\frac{f y}{200000}+0,003\right.}=\frac{600}{600+f y}$

$\mathrm{C}_{\mathrm{b}}=\mathrm{T}_{\mathrm{b}}$

$0,85 . f^{\prime} \mathrm{c} \cdot \mathrm{a}_{\mathrm{b}} \cdot \mathrm{r}=\mathrm{As}$. $\mathrm{fy}$

$0,85 \cdot f^{\prime} \mathrm{c} \cdot \beta_{1} \cdot \mathrm{c}_{\mathrm{b}} \cdot \mathrm{r}=\rho_{\mathrm{b}}$.b.d.fy $\quad$ dimana

$: \rho_{\mathrm{b}}=\frac{A s b}{b . d}$

Diperoleh: $\rho_{\mathrm{b}}=\frac{0,85 \cdot f^{\prime} c}{f y} \beta_{1} \frac{c_{b}}{d}\left(\frac{r}{b}\right)$

Atau $\rho_{\mathrm{b}}=\frac{0,85 . f^{\prime} c}{f y} \beta_{1} \frac{600}{600+f y}\left(\frac{r}{b}\right)$

Lebih lanjut, nilai

$\mathrm{c}_{\mathrm{b}}=\frac{a_{b}}{\beta_{1}}=\frac{A_{s b} f_{y}}{0,85 f_{c}^{\prime} \beta_{1} r}=\frac{\rho_{b} f_{y} d}{0,85 f_{c}^{\prime} \beta_{1}}\left(\frac{b}{r}\right)$

\section{Keadaan terkendali Tarik}

Diselesaikan dengan cara kekuatan batas (Gambar 4.2)

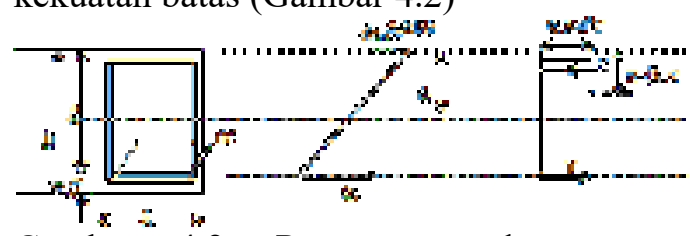

Gambar 4.2. Penampang dengan diagram regangan dan tegangan keadaan terkendali tarik

Dengan cara yang identik dengan saat kondisi setimbang:

$$
\mathrm{c}=\frac{\rho f_{y} d}{0,85 f_{c}^{\prime} \beta_{1}}(\mathrm{~b} / \mathrm{r})
$$

Dari kedua persamaan $\mathrm{c}$ dan $\mathrm{c}_{\mathrm{b}}$, dapat dinyatakan : $\frac{c}{c_{b}}=\frac{\rho}{\rho_{b}}$, apabila kedua ruas dibagi

$\mathrm{d}$, maka diperoleh:

$$
\frac{c}{d}=\frac{\rho}{\rho_{b}} \frac{c_{b}}{d}(\mathrm{~b} / \mathrm{r})
$$

Dari gambar diatas, diperoleh:c/d= $\frac{0,003}{\left(\varepsilon_{t}+0,003\right)}$, serta telah didapatkan pula $c_{b}=\frac{0,003}{\left(f_{y} / E_{s}+0,003\right)} \mathrm{d}$

sehingga lebih lanjut:

$$
\frac{c}{d}=\frac{\rho}{\rho_{b}} \frac{c_{b}}{d}\left(\frac{b}{r}\right) \frac{\rho}{\rho_{b}}\left(\frac{b}{r}\right) \frac{0,003}{\left(f_{y} / E_{s}+0,003\right)}
$$

Susun kembali, sehingga :

$$
\frac{\rho}{\rho_{b}}=\frac{0,003+f_{y} / E_{s}}{\left(\varepsilon_{t}+0,003\right)}\left(\frac{r}{b}\right)
$$

Dalam desain balok atau komponen struktur lentur lainnya, batas 
maksimum rasio tulangan dapat diambil dengan menggunakan nilai $\varepsilon_{\mathrm{t}}=0,005$, sehingga:

$$
\rho_{\text {maks }}=\frac{0,003+f_{y} / E_{s}}{\left(\varepsilon_{t}+0,003\right)} \rho_{b}
$$

Dimana $\varepsilon_{t}=0,005$

Jika tulangan dengan $\mathrm{f}_{\mathrm{y}}=400 \mathrm{MPa}$ dan $\varepsilon_{\mathrm{t}}=0,005$ dan

$$
\begin{aligned}
\rho_{\text {maks }} & =\frac{0,003+{ }^{f_{y}} / E_{s}}{(0,008)} \rho_{b}(r / b) \text { atau } \\
\rho_{\text {maks }} & =0,625 \rho_{b}(\mathrm{r} / \mathrm{b})
\end{aligned}
$$

\section{Kuat momen nominal}

Kembali perhatikan Gambar 4.2di atas, diperoleh:

Gaya tekan akibat blok tekan beton, $\mathrm{C}$ $=0,85 . f^{\prime}$. $\cdot r$.a

Gaya tarik akibat tulangan baja, $\mathrm{T}=$ As. $f_{\mathrm{y}}$

Sesuai hukum kesetimbangan gaya dalam penampang, yakni $\mathrm{C}=\mathrm{T}$, maka diperoleh, $\mathrm{a}=\frac{A s . f y}{0,85 . f^{\prime} c . r}$ sehingga momen nominal, $\mathrm{Mn}=\mathrm{A}_{\mathrm{s}} . \mathrm{f}_{\mathrm{y}}$ (d-1/2a)atau, $\mathrm{M}_{\mathrm{n}}=\mathrm{A}_{\mathrm{s}} \cdot \mathrm{f}_{\mathrm{y}}\left(\mathrm{d}-0,59 \frac{A s \cdot f y}{f^{\prime} c . r}\right)$

Hubungan Sudut Kemiringan dan Nilai Faktor reduksi
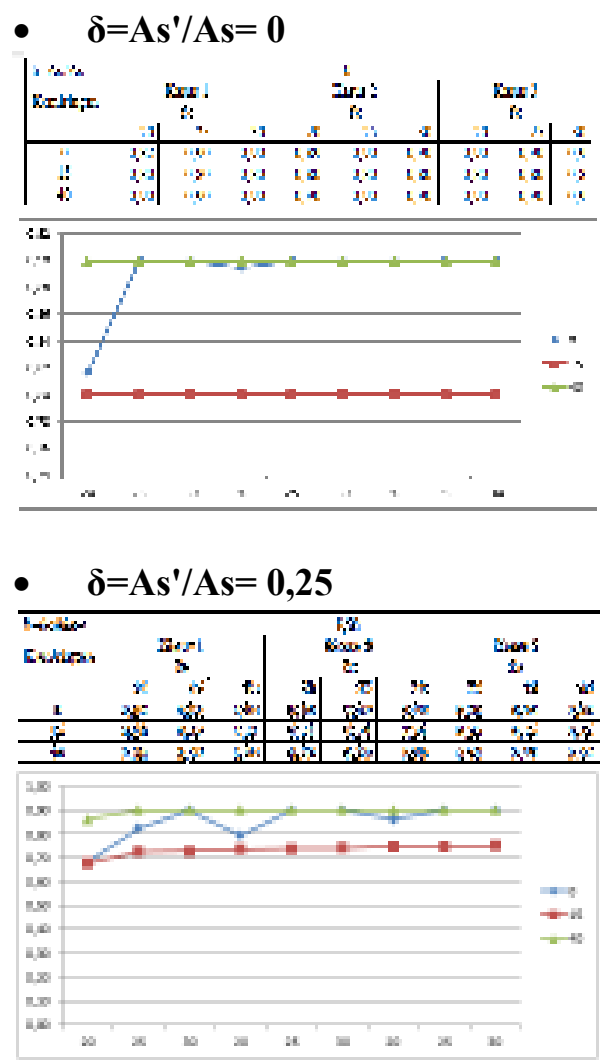

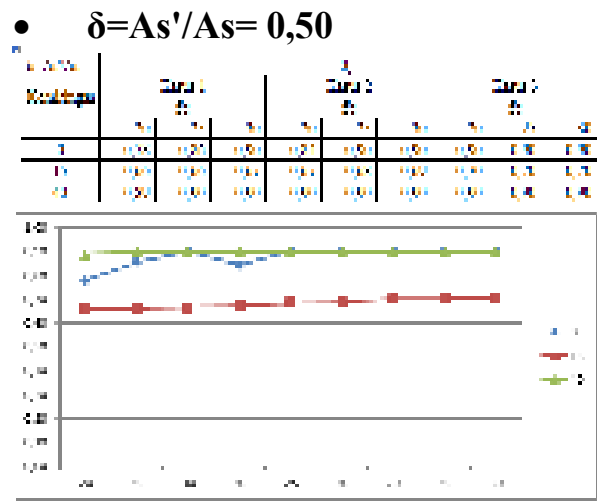

$$
\text { - } \delta=A s^{\prime} / A s=0,75
$$
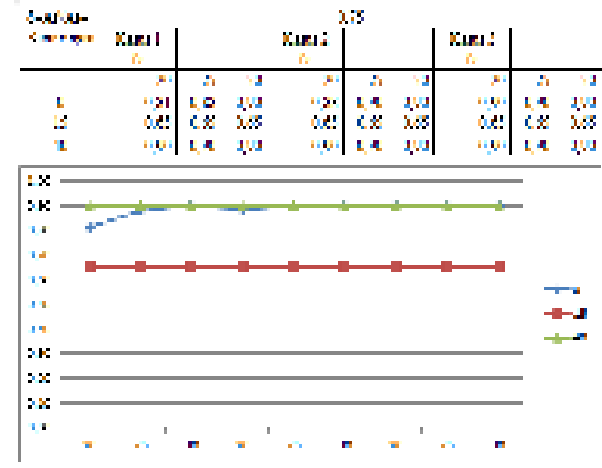

\section{Kajian Kondisi Abutmen Eksisting}

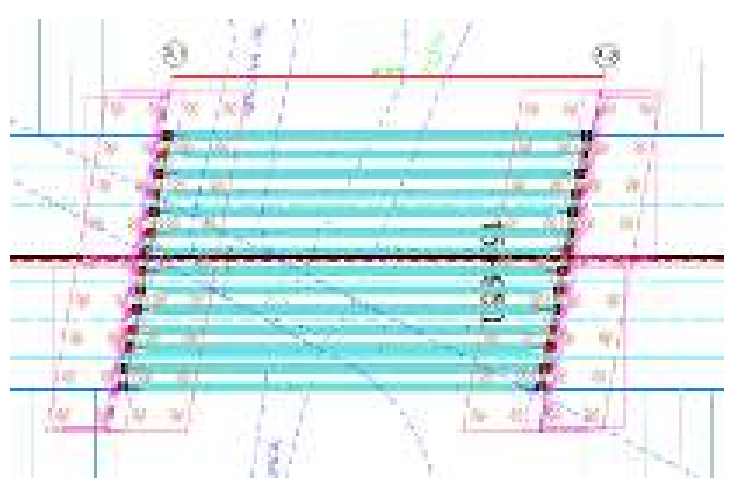

Gambar 4.4 Eksising Abutmen

- Data - data Penampang

$$
\begin{aligned}
& \text { As'/AS }=0,99 \\
& \mathrm{Fy}=420 \\
& \mathrm{Fc}^{\prime}=30 \mathrm{Mpa} \\
& \text { Alfa }=10 \text { derajat }
\end{aligned}
$$

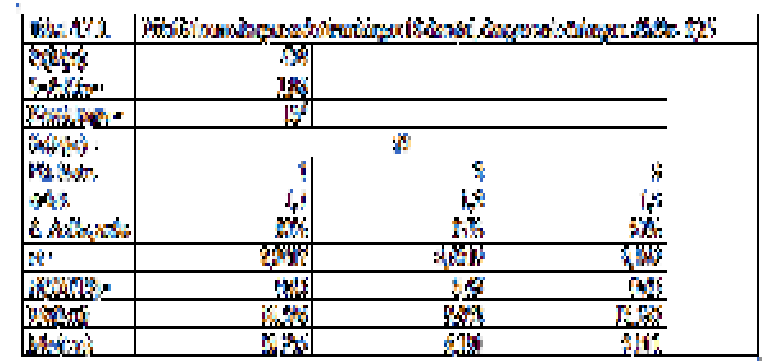


Memperhatikan tabel diatas, bahwa untuk rasio tulangan tekan $, \delta=0,75$ atau balok bertulangan rangkap, Dapat di simpulkan maka untuk kasus dimana rasio dimensi balok $30 \mathrm{Mpa}$, maka factor reduksi lentur adalah angka dibawah 0,8 . Dan factor reduksi lentur adalah dibawah 0,9 , terkendali tarik.

\section{KESIMPULAN}

Dapat saya simpulkan dari hasil penelitian saya tentang Jalan Tol Pandaan - Malang :

1. Jika pada saat kemiringan 0 derajat dapat disimpulkan terkendali tekan.

2. Jika pada saat kemiringan 15 derajat dapat disimpulkan terkendali tekan untuk rasio tulangan 0,0 dan 0,25 , sedangkan untuk rasio tulangan 0,5 dan $\quad 0,75$ terkendali tarik.

3. Jika pada saat kemiringan 40 derajat dapat di simpulkan terkendali tekan.

Jika pada saat kondisi eksisting di lapangan dengan kemiringan 10 derajat dengan rasio tulangan 0,75 dapat saya simpulkan terkendali tarik.

\section{REFERENSI}

[1] Anonim; 2016 Pembebanan Jembatan ; SNI - 1725; BADAN STANDARDISASI NASIONAL, Jakarta.

[2] Bowles,josephe; Analisa dan Desain Pondasi Jilid 2; Erlangga, Jakarta.

[3] Nasution,A (2009). “Analisa dan Desain Struktur Beton Bertulang".ITB. Bandung.

[4] Priyono, P. (1994). Diktat Kuliah Struktur Beton I (Berdasarkan SNI 03 - 2847 2002). Universitas Muhammadiyah Jember, Jember.

[5] Renaningsih,2016,Analisis Penampang Beton Bertulang Persegi
Menggunankan

PCACOL,Jurnal Ilmiah Teknik Sipil.

[6] Setiawan, A. (2013). Perencanaan Struktur Baja dengan Metode LRFD (berdasarkan SNI 02-17292002",2nded. Erlangga, Jakarta

[7] Vis,W.C dan Gideon k. (1993). "Dasar-dasar Perencanaan Beton Bertulang Berdasarkan SK.SNI T-151991-03'’Erlangga Jakarta. 